HEAD AND NECK

\title{
Elective neck dissection during salvage surgery after radiotherapy in patients with head and neck squamous cell carcinoma
}

\author{
Svuotamento linfonodale cervicale elettivo nella chirurgia di salvataggio dopo \\ radioterapia in pazienti con carcinoma a cellule squamose del distretto testa-collo
}

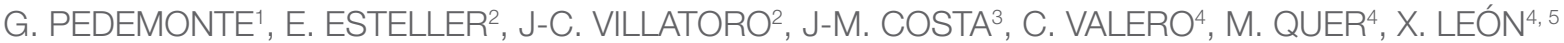 \\ ${ }^{1}$ Otorhinolaryngology Department, Hospital Mutua de Terrassa, Terrassa, Barcelona, Spain; ${ }^{2}$ Otorhinolaryngology \\ Department, Hospital General de Catalunya, Universitat Internacional de Catalunya, Sant Cugat del Vallès, \\ Barcelona, Spain; ${ }^{3}$ Otorhinolaryngology Department, Hospital de Sant Joan Despí Moisès Broggi, Sant Joan Despí, \\ Barcelona, Spain; ${ }^{4}$ Otorhinolaryngology Department, Hospital de la Santa Creu i Sant Pau, Universitat Autònoma \\ de Barcelona, Barcelona, Spain; ${ }^{5}$ Centro de Investigación Biomédica en Red de Bioingeniería, Biomateriales y \\ Nanomedicina (CIBER-BBN), Madrid, Spain
}

\begin{abstract}
SUMMARY
Elective neck dissection in patients with recurrent head and neck squamous cell carcinoma (HNSCC) without evidence of neck disease (crN0) is poorly defined. A retrospective review was carried out on $165 \mathrm{crN} 0$ patients treated with salvage surgery and elective neck dissection. Multivariate Cox analysis and recursive partitioning analysis were used to evaluate prognostic factors. The frequency of occult neck node metastases in the neck dissection (rpN+) was 16.4\%. The risk of occult metastases for glottic rpT1-T2 recurrences was 5.9\%, for glottic rpT3-T4 recurrences $13.2 \%$, for non-glottic rpT1-T2 recurrences $16.1 \%$ and for locally advanced (rpT3-T4) non-glottic recurrences $31.1 \%$. Patients with occult neck node metastases ( $\mathrm{rpN}+$ ) had a 5-year adjusted survival rate of 38.1\%, while patients without nodal disease (rpN0) had a 5-year adjusted survival rate of 71.1\% ( $\mathrm{p}=0.0001)$. Elective neck dissection can be omitted in crN0 patients with $\mathrm{rT} 1-\mathrm{T} 2$ glottic recurrence. We consider it advisable to perform elective neck dissection in all other situations.
\end{abstract}

KEY WORDS: Salvage surgery • Elective neck dissection • Occult neck node metastases $\bullet$ Head and neck cancer

\section{RIASSUNTO}

Lo svuotamento linfonodale cervicale elettivo in pazienti con recidiva di carcinoma a cellule squamose del distretto testa-collo, senza evidenza clinico-radiologica di metastasi linfonodale (crNO), è scarsamente descritto in letteratura. Per questa ragione è stata condotta una revisione retrospettiva di una coorte di 165 pazienti crNO, sottoposti a chirurgia di salvataggio e svuotamento cervicale elettivo. Per la valutazione dei fattori prognostici sono state utilizzate l'analisi multivariata di Cox e l'analisi di partizione ricorsiva. Successivamente allo svuotamento cervicale, la frequenza di metastasi linfonodali occulte $(r p N+)$ è stata del 16,4\%. Il rischio di metastasi occulte, in caso di tumori glottici recidivanti, è stato del 5,9\% per le categorie rpT1-T2, e del 13.2\% per le categorie rpT3-T4. Per quanto riguarda i tumori non-glottici recidivanti, il rischio di metastasi occulte è stato del 16,1\% per le categorie rpT1-T2, mentre in caso di neoplasie localmente avanzate (rpT3-T4) è stato del 31,1\%. La sopravvivenza a 5anni dei pazienti con metastasi linfonodali occulte (rpN +) é stata del 38,1\%, mentre la sopravvivenza a 5 anni dei pazienti che non hanno presentato invasione linfonodale (rpN0) è stata del 71,1\% (con una differenza statisticamente significativa, $p=0,0001$ ). Lo svuotamento cervicale potrebbe essere omesso in pazienti con neoplasia glottica recidiva crNO rT1-T2. Al contrario, alla luce di questi risultati, riteniamo che sia consigliabile eseguire questa tecnica in tutte le altre situazioni.

PAROLE CHIAVE: Chirurgia di salvataggio • Svuotamento laterocervicale • Metastasi cervicali occulte • Tumore del distretto testa-collo

Acta Otorhinolaryngol Ital 2018;38:86-93

\section{Introduction}

There is no doubt about the benefits of performing therapeutic neck dissection during salvage surgery in patients with local recurrence of head and neck squamous cell carcinoma (HNSCC) after radiotherapy or chemoradiotherapy and evidence of cervical metastases (crN+). However, 
the convenience of elective neck dissection in patients with local recurrence of HNSCC and no evidence of regional disease ( $\mathrm{crN} 0)$ remains unclear.

Some authors recommend performing elective neck dissection on crN0 patients during salvage surgery ${ }^{1-4}$. Others consider it appropriate to carry out elective neck dissection only in patients with locally advanced recurrence or clinically positive nodes at the time of initial diagnosis of the tumour ${ }^{56}$. On the other hand, a group of authors do not consider it necessary to systematically perform neck dissection in crN0 patients with HNSCC local recurrence during salvage surgery due to: (i) low percentage of occult neck node metastases in these patients; (ii) good regional control achieved in patients kept under observation; (iii) increase in postoperative complications related to performing neck dissection ${ }^{7-14}$.

The goal of our study was to determine the risk of occult nodal metastases in HNSCC patients with local recurrence without evidence of neck disease (crN0), and to define the utility of performing elective neck dissection during salvage surgery in this group of patients.

\section{Materials and methods}

We conducted a retrospective study using a database that has prospectively collected data on epidemiology, treatment and follow-up of all patients with HNSCC treated at our centre since $1985^{15}$. Eligible patients met the following criteria: (1) pathological diagnosis of HNSCC of the oral cavity, oropharynx, hypopharynx, or larynx treated with radical intention between 1992 and 2012; (2) primary tumour treated with radiotherapy or chemoradiotherapy; (3) not having undergone a neck dissection during primary treatment of the tumour; (4) pathologically confirmed recurrence of the tumour at the primary site; (5) clinical and radiological N0 at the time of salvage surgery; (6) salvage surgery of the local recurrence with an elective neck dissection; (7) minimum follow-up of 2 years after salvage surgery unless recurrence or death. Patients were staged using the 7th edition of the TNM classification at the time of initial treatment and at the time of salvage surgery ${ }^{16}$. An oncology panel evaluated all patients and recommended salvage surgery and neck dissection. All procedures were reviewed by the Institutional Review Board of our centre. The study conforms to the principles outlined in the Declaration of Helsinki.

All patients included had a radiologic screening of the NO neck. A CT scan was routinely used for patients with a laryngeal or hypopharyngeal tumour, while for patients with an oral cavity or an oropharyngeal tumour MRI was used preferentially. In all cases, the radiologic report ex- cluded the presence of positive or suspicious neck nodes. None of our patients was studied with PET-CT.

In our centre, elective neck dissection was performed systematically in patients with local recurrence when salvage surgery was carried out using an open cervical approach. One hundred and sixty-five patients who met the inclusion criteria were included in the study. Table I shows location of the primary tumour, local and regional extension of the primary tumour, local and regional management during primary treatment, local extension of the recurrence and salvage surgery. For early glottic carcinomas, the field of radiotherapy was limited to the central neck, avoiding prophylactic irradiation of the cervical neck nodes. One hundred and three patients received radiotherapy over the neck nodes during the treatment of the primary head and neck tumour. Patients with N0 primary tumour $(n=69)$ received 50 to $55 \mathrm{~Gy}$ as a total dose of radiotherapy over the neck. The group of $\mathrm{N}+$ patients $(\mathrm{n}=34)$ received 65 to $72 \mathrm{~Gy}$. Local recurrences were diagnosed during the first 2 years of follow-up after treatment of the primary tumour in $83.8 \%$ of cases.

Table I. Characteristics of patients included in the study.

\begin{tabular}{llrr} 
& & N & (\%) \\
Sex & Men & 157 & $(95.2 \%)$ \\
& Women & 8 & $(4.8 \%)$ \\
Age: mean / & $58.9 /$ 10.1 years & & \\
standard deviation & & & \\
Primary tumour & Oral cavity & 14 & $(8.5 \%)$ \\
location & Oropharynx & 18 & $(10.9 \%)$ \\
& Hypopharynx & 7 & $(4.2 \%)$ \\
& Supraglottis & 36 & $(21.8 \%)$ \\
Primary tumour & Glottis & 90 & $(54.5 \%)$ \\
local extension & T1-2 & 112 & $(67.9 \%)$ \\
Primary tumour & T3-4 & 53 & $(32.1 \%)$ \\
regional extension & N0 & 131 & $(79.4 \%)$ \\
Primary tumour & N+ & 34 & $(20.6 \%)$ \\
treatment & RT & 145 & $(87.9 \%)$ \\
Primary tumour & CT-RT & 20 & $(12.1 \%)$ \\
neck management & Observation & 62 & $(37.6 \%)$ \\
Recurrence & Radiotherapy & 103 & $(62.4 \%)$ \\
local extension & rT1-2 & 82 & $(49.7 \%)$ \\
Salvage surgery & rT3-4 & 83 & $(50.3 \%)$ \\
& Total laryngectomy & 88 & $(53.3 \%)$ \\
& Laryngopharyngectomy & 20 & $(12.1 \%)$ \\
& Partial laryngectomy & 29 & $(17.6 \%)$ \\
& Pelviglossectomy & 19 & $(11.7 \%)$ \\
& Bucopharyngectomy & 9 & $(5.5 \%)$ \\
\hline & & &
\end{tabular}


All patients underwent an elective neck dissection during salvage surgery. A total of 221 selective neck dissections at levels II-IV, 26 of levels I-III and 13 of levels II-III were carried out. For patients with a glottic tumour with subglottic extension $(n=13)$ a dissection of the paratracheal nodes (level VI) was also included. Bilateral neck dissection was performed in $57.6 \%$ of patients.

We used the Chi-square or Fisher's exact test in univariate analysis, and a logistic regression model in the multivariate analysis. Patients were classified according to a recursive partitioning analysis with a classification and regression tree (CRT) method, considering the appearance of occult neck node metastases in the neck dissection ( $\mathrm{rpN}+$ ) as the dependent variable. Location of the primary tumour, local and regional extension of the primary tumour, local extension of the recurrence, and initial management of the neck were considered as independent variables. We reviewed the pathologic reports of neck dissections of the $\mathrm{rpN}+$ patients, collecting data about the size of the positive neck nodes. Micrometastases were defined as microscopic deposits of malignant cells smaller than 2-3 mm in diameter.

Survival curves were calculated using the Kaplan-Meier technique. Differences in survival were compared using the log-rank test.

\section{Results}

Occult neck node metastases were found during neck dissection (crN0/rpN+) in 27 patients $(16.4 \%)$. Of the 27 patients with positive neck dissection, 14 (51.9\%) were found to have only one pathological neck node (rpN1), 10 $(37.0 \%)$ had 2 or more ipsilateral metastatic neck nodes (rpN2b) and $3(11.1 \%)$ showed bilateral nodal involvement $(\mathrm{rpN} 2 \mathrm{c})$. Six of the rpN+ patients $(22.2 \%)$ had pathological evidence of nodes with extracapsular tumour spread.

Eleven patients had micrometastases, 14 had metastatic neck nodes up to $1 \mathrm{~cm}$ and only 2 had neck node metastases larger than $1 \mathrm{~cm}$. In both cases of neck node metastases greater than $1 \mathrm{~cm}$, the pathologic report pointed out that the size of the neck nodes was about $2 \mathrm{~cm}$, and in one case it had necrosis. We reviewed the images of these two patients (a CT and a MRI corresponding to one patient with a hypopharyngeal crT4N0 tumour and one patient with an oropharyngeal crT2N0 tumour, respectively), and did not find any radiological evidence of neck disease.

Table II shows the percentage of patients with occult neck node metastases depending on the location of the primary tumour, local and regional extension of the primary tumour, neck management during the initial treatment and local extension of the recurrence. According to the results of uni- variate analysis, the only variable significantly associated with the appearance of occult neck node metastases was the local extension of the tumour at the time of recurrence. None of the variables had significant prognostic influence when included in the multivariate analysis. Nevertheless, a higher frequency of occult neck node metastases was found in patients with locally advanced recurrences (rT3-4), and a lower frequency was found in those with glottic tumours. Information regarding HPV status was available for 17 of the 18 patients with oropharyngeal carcinoma. Only one patient was HPV positive, without showing evidence of occult metastasis in the neck dissection. The frequency of occult neck node metastasis in patients with HPV negative tumours was $18.8 \%(3 / 16)$.

Considering the appearance of occult neck node metastases as the dependent variable, the CRT method classified patients according to the initial tumour location and the extension of the recurrence. A total of four terminal nodes were obtained using this classification method (Fig 1). Due to the similar risk of occult neck node metastases between nodes 2 (rT3-4 glottic carcinoma) and 3 (rT1-2 non-glottic carcinoma), both nodes were grouped in one category. Table III shows the categories according to the risk of appearance of occult neck node metastases as defined by the CRT classification system.

The three patients with early glottic recurrences (rT1-2) who had occult neck node metastases were specifically reviewed. All three patients had recurrences with subglottic extension of the tumour (rT2). In two cases, the neck node metastases appeared in the anterior neck dissection, and not in the lateral neck dissection. In the third case, the occult neck node metastases appeared in the lateral selective neck dissection.

Survival was analysed according to the risk of having occult neck node metastases at neck dissection. Figure 2 shows adjusted survival curves after salvage surgery for patients without occult neck node metastases (rpN0, $\mathrm{n}=138$ ), and for patients with occult neck node metastases $(\mathrm{rpN}+\mathrm{n}=27)$. Five-year adjusted survival was $71.1 \%$ (CI 95\%: 62.9-79.3\%) for rpN0 patients, and $38.1 \%$ (CI 95\%: $18.4-57.8 \%$ ) for rpN+ patients. Significant differences in survival were found according to the pathological state of the neck dissection $(\mathrm{P}=0.0001)$.

\section{Discussion}

The management of nodal areas in patients without clinical or radiological evidence of cervical disease (crN0) treated with salvage surgery after local failure of the previous treatment with radiotherapy or chemoradiotherapy is a controversial topic. The incidence of occult neck node 
Table II. Risk of occult neck node metastases in elective neck dissection according to different clinical variables.

\begin{tabular}{|c|c|c|c|c|c|c|c|}
\hline \multirow{3}{*}{ Primary tumour location } & \multirow[b]{3}{*}{ Oral cavity $(n=14)$} & \multicolumn{3}{|c|}{ Univariate analysis } & \multicolumn{3}{|c|}{ Multivariate analysis } \\
\hline & & \multicolumn{2}{|c|}{$\mathrm{rpN}+$} & \multirow{2}{*}{$\begin{array}{c}P \\
0.088\end{array}$} & \multirow{2}{*}{$\begin{array}{l}\text { HR } \\
1\end{array}$} & \multirow[t]{2}{*}{ Cl 95\% } & \multirow[t]{2}{*}{$P$} \\
\hline & & 3 & $(21.4 \%)$ & & & & \\
\hline & Oropharynx $(n=18)$ & 4 & $(22.2 \%)$ & & 0.94 & $0.16-5.41$ & 0.946 \\
\hline & Hypopharynx $(\mathrm{n}=7)$ & 2 & $(28.6 \%)$ & & 1.16 & $0.13-10.12$ & 0.891 \\
\hline & Supraglottis $(n=37)$ & 10 & $(27.0 \%)$ & & 0.89 & $0.18-4.33$ & 0.892 \\
\hline & Glottis $(n=89)$ & 8 & $(9.0 \%)$ & & 0.23 & $0.04-1.28$ & 0.095 \\
\hline \multirow[t]{2}{*}{ Primary tumour local extension } & $\mathrm{T} 1-2(\mathrm{n}=112)$ & 14 & $(12.5 \%)$ & 0.051 & 1 & & \\
\hline & T3-4 $(n=53)$ & 13 & $(24.5 \%)$ & & 1.23 & $0.40-3.82$ & 0.711 \\
\hline \multirow{2}{*}{$\begin{array}{l}\text { Primary tumour regional } \\
\text { extension }\end{array}$} & No $(n=131)$ & 20 & $(15.3 \%)$ & 0.455 & 1 & & \\
\hline & $N+(n=34)$ & 7 & $(20.6 \%)$ & & 0.55 & $0.17-1.78$ & 0.324 \\
\hline \multirow{2}{*}{$\begin{array}{l}\text { Recurrence } \\
\text { local extension }\end{array}$} & $\mathrm{rT} 1-2(\mathrm{n}=82)$ & 8 & $(9.8 \%)$ & 0.023 & 1 & & \\
\hline & rT3-4 $(n=83)$ & 19 & $(22.9 \%)$ & & 2.47 & $0.90-6.80$ & 0.079 \\
\hline \multirow{2}{*}{$\begin{array}{l}\text { Primary tumour neck } \\
\text { management }\end{array}$} & Observation $(n=62)$ & 6 & $(9.7 \%)$ & 0.072 & 1 & & \\
\hline & Radiotherapy ( $\mathrm{n}=103$ ) & 21 & $(20.4 \%)$ & & 0.78 & $0.18-3.78$ & 0.739 \\
\hline
\end{tabular}

metastases in elective neck dissection performed in these patients ranges between $0 \%$ and $25 \%$ in the different published series (Table IV). Variability in the percentage of occult neck node metastases may be attributed to the different types of patients included in each study. Some series evaluated patients with laryngeal tumours ${ }^{1245811-1417}$, including different proportions of patients with glottic

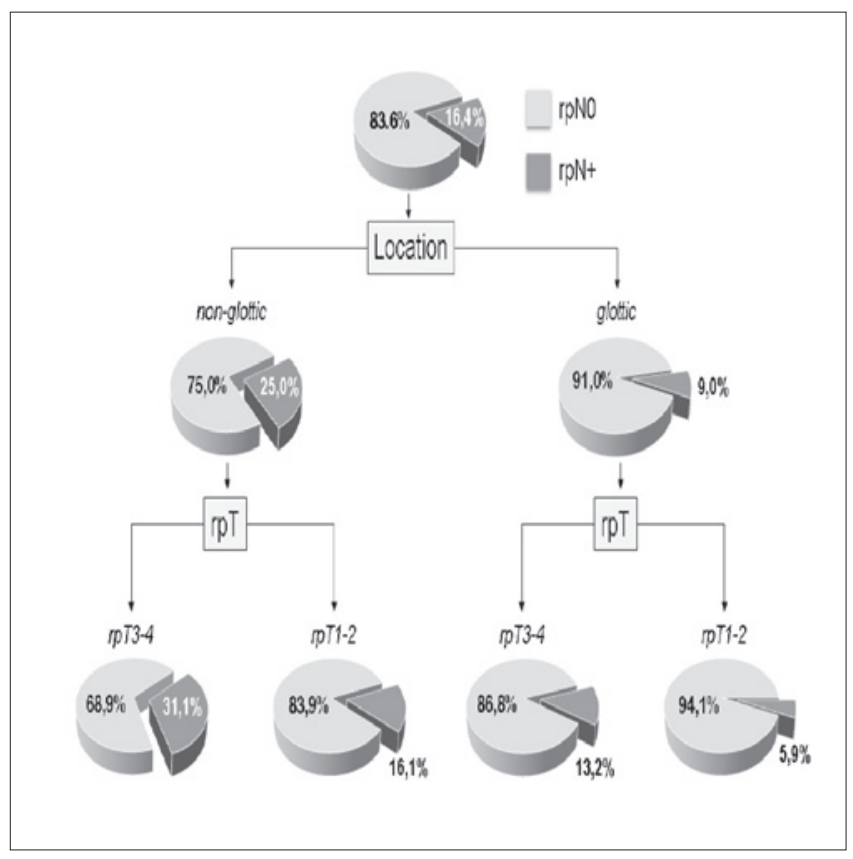

Fig. 1. Classification obtained with the classification and regression tree method. tumours, while in other series several head and neck locations were involved 379101819 . Moreover, some series included patients with locally advanced tumours or recurrences ${ }^{410-12}$, while others preferentially evaluated patients with more limited tumours 57818 .

As a result, conclusions by different authors are highly variable. A number of authors recommend performing elective neck dissection in crN0 patients when salvage surgery is carried out. Others only consider performing neck dissection in patients with locally advanced recurrent tumours, in patients with tumours localised in the supraglottis, or in patients with initial nodal involvement. Finally, based on the low incidence of occult neck node metastases and the acceptable results achieved with the policy of neck observation, a group of authors do not consider it necessary to perform elective neck dissection at the time of salvage surgery (Table IV).

One of the reasons to perform elective neck dissection in crN0 patients during salvage surgery after treatment with radiotherapy or chemoradiotherapy would be that the more aggressive biological behavior of the tumour involved in the recurrence is associated with an increased risk of occult neck node metastases. Additionally, as initial treatment with radiotherapy or chemoradiotherapy failed to eradicate the primary tumour, the persistence of subclinical disease at the cervical level could be possible. Moreover, in case of nodal recurrence, control options with a second salvage surgery at the cervical level are very limited ${ }^{2021}$.

The authors who advocate for a "wait and see" policy argue that due to the low incidence of occult neck node 
Table III. Classification of patients according to the risk of occult neck node metastases in elective neck dissections.

\begin{tabular}{llcc} 
Category & Low risk & $\begin{array}{c}\text { Number of } \\
\text { patients }\end{array}$ & $\begin{array}{c}\text { \% 0ccult } \\
\text { metastases }\end{array}$ \\
rT1-2 & 51 & $5.9 \%$ \\
Intermediate risk & $\begin{array}{l}\text { Glottic tumours } \\
\text { rT3-4 } \\
\text { Non-glottic tumours } \\
\text { rT1-2 }\end{array}$ & 69 & $14.5 \%$ \\
High risk & $\begin{array}{l}\text { Non-glottic tumours } \\
\text { rT3-4 }\end{array}$ & 45 & \\
\hline
\end{tabular}

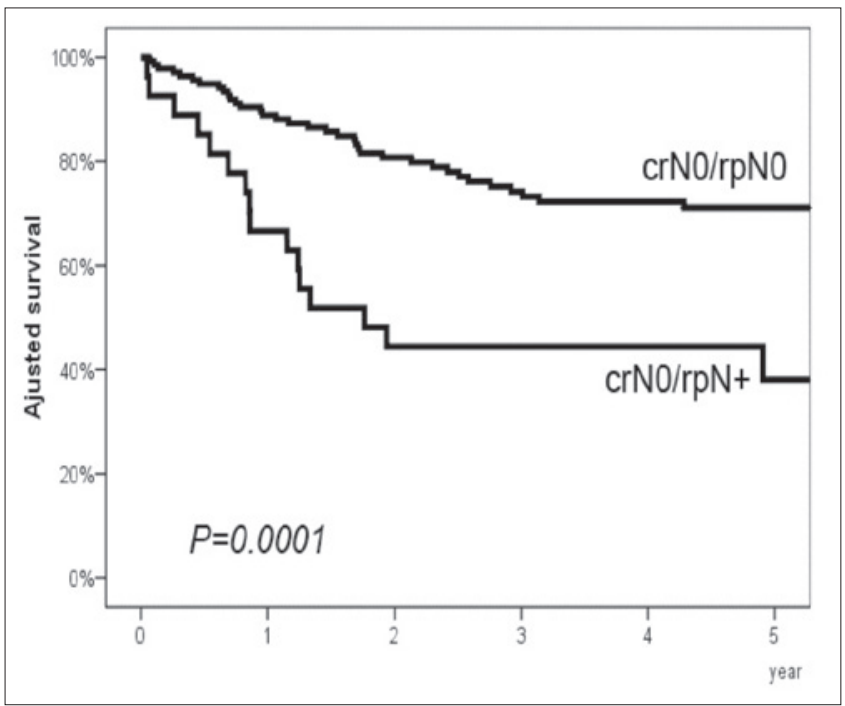

Fig. 2. Adjusted survival of patients with HNSCC local recurrence according to the presence of occult neck node metastases.

metastases, there is no evidence that the systematic addition of elective neck dissection increases regional control of the tumour or improves prognosis. In addition, some authors found that performing elective neck dissection involved an increase in postoperative complications ${ }^{8}{ }^{12-14}$. Sanabria et al. ${ }^{22}$ reviewed the results reported in the literature and concluded that the observation policy would be justified for patients with glottic tumours classified originally as early tumours (T1-T2), and also in recurrent early tumours (rT1-2). For patients with advanced laryngeal recurrences (rT3-4) and non-glottic tumours, an elective neck dissection should be considered.

Our study analysed a wide range of patients with head and neck tumours of different locations. They were treated with a protocol that included the systematic performance of elective neck dissection in crN0 patients who are candidates for open salvage surgery. We reached conclusions similar to those of Sanabria et al. ${ }^{22}$. The recursive partitioning analysis classified patients according to the risk of having neck node metastases, and three categories were defined. Patients with limited glottic recurrences (rT1-2) showed a relatively low risk of subclinical nodal involvement $(5.9 \%)$, so that the observation policy for the neck would be justified. In case of recurrence with subglottic involvement, performing dissection of lymph nodes along the recurrent laryngeal nerves would be indicated. Patients with advanced glottic recurrences (rT3-4) or limited tumour recurrences located outside the glottis (rT1-2) showed an intermediate risk of nodal involvement $(14.5 \%)$. Finally, in patients with advanced tumour recurrence with non-glottic location (rT3-4), the risk of occult neck node metastases was high $(31.1 \%)$. Based on our results, we consider it justified to systematically perform elective neck dissection in patients whose risk of having lymph node involvement is intermediate or high.

In the majority of rpN+ cases, the tumour burden was low. Eleven patients had micrometastases, and 14 patients had metastatic nodes up to $1 \mathrm{~cm}$. However, 2 patients had $2 \mathrm{~cm}$ neck nodes. We reviewed the radiological images carried out prior to the salvage surgery, and did not find any evidence of nodal neck disease. A progression of the tumour in the period between the radiologic study and the salvage surgery could justify the inconsistency between the image study and the pathologic report in those two patients.

One aspect to consider is the influence of radiation fields in the appearance of neck node metastases in case of recurrence. Radiotherapy causes loss of lymphoid tissue and its replacement by fibrous tissue ${ }^{23}{ }^{24}$. These changes may serve as a barrier for lymphatic dissemination in case of local recurrence in patients who were previously treated with radiotherapy. However, in a study performed by Solares et al. ${ }^{3}$ where the incidence of occult neck node metastases was assessed in patients who were treated with primary radiotherapy or chemoradiotherapy and had a local recurrence or a second primary tumour, the incidence and anatomic distribution of subclinical neck node metastases was comparable to what was reported in untreated N0 necks. The authors concluded that previous treatment with radiotherapy did not change the anticipated pattern of neck node metastases in patients with local recurrence after primary treatment with radiotherapy. Similarly, Deganello et al. ${ }^{13}$ did not find significant differences between previous treatment with neck radiotherapy and the risk of occult neck node metastases in crN0 patients treated with salvage surgery.

According to our results, the appearance of occult neck node metastases in neck dissection during salvage surgery was significantly associated with lower survival, as in patients with HNSCC and neck node metastases at initial treatment ${ }^{25}$. 
Table IV. Percentage of occult neck node metastases in crNO patients and suggestions for performing elective neck dissection obtained from published studies.

\begin{tabular}{|c|c|c|c|c|c|}
\hline Author (year) & Location & $\mathrm{N}$ & Treatment & $\begin{array}{l}\text { \% Occult metastases } \\
\text { (rpN+/neck dissections) }\end{array}$ & Elective neck dissection \\
\hline Wax $(1999)^{2}$ & Larynx & 34 & RT & $17 \%(6 / 34)$ & Yes \\
\hline Solares $(2005)^{3}$ & $\mathrm{H} \& \mathrm{~N}$ & 69 & RT & $25 \%(17 / 69)$ & Yes \\
\hline Yao $(2005)^{5}$ & Larynx & 63 & RT & $12 \%(5 / 41)$ & Only rT3/4 and supraglottis \\
\hline Temam $(2005)^{10}$ & $\mathrm{H} \& \mathrm{~N}$ & 30 & RT & $3 \%(1 / 30)$ & Not necessary \\
\hline Farrag $(2006)^{11}$ & Larynx & 51 & RT & $12 \%(4 / 34)$ & Not necessary \\
\hline Dagan $(2010)^{7}$ & $\mathrm{H} \& \mathrm{~N}$ & 57 & RT & $10 \%(4 / 40)$ & Not necessary \\
\hline Bohannon (2010)12 & Larynx & 71 & RT & $8 \%(3 / 38)$ & Not necessary \\
\hline Amit $(2013)^{4}$ & Larynx & 42 & RT & $19 \%(8 / 42)$ & Yes \\
\hline Yirmibesoglu (2013) ${ }^{9}$ & $\mathrm{H} \& \mathrm{~N}$ & 44 & RT & $10 \%(3 / 30)$ & Not necessary \\
\hline Lee $(2013)^{17}$ & $\mathrm{H} \& \mathrm{~N}$ & 149 & RT/Sur & $8 \%(6 / 80)$ & Only initial $\mathrm{N}+$ and early recurrence \\
\hline Basheeth $(2013)^{8}$ & Larynx & 45 & RT & $8 \%(3 / 38)$ & Not necessary \\
\hline Prendes $(2014)^{18}$ & $\mathrm{H} \& \mathrm{~N}(\mathrm{~N}+)$ & 16 & RT & $40 \%(4 / 10)$ & Yes \\
\hline Hilly $(2013)^{6}$ & Larynx & 87 & RT & $13 \%(6 / 48)$ & rT3-4 \\
\hline Deganello $(2014)^{13}$ & Larynx & 110 & RT & $0 \%(0 / 7)$ & Not necessary \\
\hline Pezier $(2014)^{14}$ & Larynx & 28 & RT & $7 \%(2 / 28)$ & Not necessary \\
\hline Koss $(2014)^{16}$ & Larynx & 68 & RT & $28 \%(19 / 68)$ & Yes \\
\hline
\end{tabular}

H\&N: Head and neck; RT: Radiotherapy: Sur: Surgery

Only one of our patients with an oropharyngeal carcinoma treated with salvage surgery was HPV positive. We think that the low proportion of HPV positive oropharyngeal tumours in our study is a consequence of the low percentage of HPV positive patients in our geographical setting ${ }^{26}{ }^{27}$, coupled with the high control of the disease achieved with treatment in those HPV positive tumours. It would be interesting to investigate the frequency of occult neck node metastases in elective neck dissections in oropharyngeal patients in function of HPV status of the tumour.

The main limitation of our study is its retrospective nature and the wide period of time it covers. Although cervical management of patients with salvage therapy has not been substantially modified, progressive improvement of $\mathrm{CT}$ and MRI over the study period may have changed the classification of crN0 patients. We do not have experience about the efficiency of PET-CT in the assessment of crN0 patients who are candidates for salvage surgery. Currently ${ }^{18}$, F-FDG PET-CT has a fundamental role in the evaluation during follow-up of patients with a HNSCC, with a higher degree of accuracy in detecting recurrences of the disease than other imaging modalities ${ }^{28} 29$. The results of a systematic review and a meta-analysis carried out by Gupta et al. ${ }^{30}$ including 30 studies (1,525 patients) assessing the diagnostic performance of ${ }^{18} \mathrm{~F}$-FDG PET and PET-CT in the assessment of response and surveillance for neck nodes in HNSCC patients, reported a high negative predictive value $(94.5 \%)$ and a suboptimal positive predictive value $(52.1 \%)$. Most studies evaluating the predictive capacity of PET/PET-CT in the neck analyse the outcome obtained after completion of radical treatment. PET-CT has been shown to be an effective diagnostic tool for detecting occult cervical metastatic nodes in patients with negative neck palpation findings in the context of the initial assessment of patients with HNSCC ${ }^{3132}$. However, there are practically no data on the prognostic capacity in the detection of ocult neck node metastasis of PET-CT in patients with local recurrence of the disease. Gilbert et al. ${ }^{33}$ carried out a study examining the sensitivity and specificity of PET-CT in patients with a laryngeal carcinoma recurrence after radiotherapy treated with a total laryngectomy and neck dissections. The authors evaluated 8 patients crN0 who had PET-CT reads that were negative, three of whom had positive nodal disease in the elective neck dissection, giving a negative predictive value of the PET-CT of $62.5 \%$. Larger studies are necessary to evaluate the efficiency of PET-CT in the detection of hidden cervical metastatic deposits in crN0 patients who are candidates for salvage surgery.

\section{Conclusions}

Based on our results, in patients without clinical or radiological evidence of lymph node involvement (crN0) we suggest to perform an elective neck dissection during salvage surgery in non-glottic rT1-T2 recurrences, and 
in locally advanced glottic and non-glottic recurrences (rT3-T4). Due to the low incidence of occult neck node metastases in crN0 patients with early glottic recurrences (rT1-T2), elective neck dissection could be omitted in these cases.

\section{Funding}

This study was funded by a grant from Instituto de Salud Carlos III (FIS 14-01819).

\section{References}

1 Yuen AP, Wei WI, Ho CM. Results of surgical salvage for radiation failures of laryngeal carcinoma. Otolaryngol Head Neck Surg 1995;112:405-9.

2 Wax MK, Touma BJ. Management of the NO neck during salvage laryngectomy. Laryngoscope 1999;109:4-7.

3 Solares CA, Fritz MA, Esclamado RM. Oncologic effectiveness of selective neck dissection in the NO irradiated neck. Head Neck 2005;27:415-20.

4 Amit M, Hilly O, Leider-Trejo L, et al. The role of elective neck dissection in patients undergoing salvage laryngectomy. Head Neck 2013;35:1392-6.

5 Yao M, Roebuck JC, Holsinger FC, et al. Elective neck dissection during salvage laryngectomy. Am J Otolaryngol 2005;26:388-92.

6 Hilly O, Gil Z, Goldhaber D, et al. Elective neck dissection during salvage total laryngectomy - a beneficial prognostic effect in locally advanced recurrent tumours. Clin Otolaryngol 2015;40:9-15.

7 Dagan R, Morris CG, Kirwan JM, et al. Elective neck dissection during salvage surgery for locally recurrent head and neck squamous cell carcinoma after radiotherapy with elective nodal irradiation. Laryngoscope 2010;120:945-52.

8 Basheeth N, O'Leary G, Sheahan P. Elective neck dissection for NO neck during salvage total laryngectomy: findings, complications, and oncological outcome. JAMA Otolaryngol Head Neck Surg 2013;139:790-6.

9 Yirmibesoglu E, Fried D, Shores C, et al. Incidence of subclinical nodal disease at the time of salvage surgery for locally recurrent head and neck cancer initially treated with definitive radiation therapy. Am J Clin Oncol 2013;36:475-80.

10 Temam S, Koka V, Mamelle G, et al. Treatment of the NO neck during salvage surgery after radiotherapy of head and neck squamous cell carcinoma. Head Neck 2005; 27:653-8.

11 Farrag TY, Lin FR, Cummings CW, et al. Neck management in patients undergoing postradiotherapy salvage laryngeal surgery for recurrent/persistent laryngeal cancer. Laryngoscope 2006;116:1864-6.

12 Bohannon IA, Desmond RA, Clemons L, et al. Management of the NO neck in recurrent laryngeal squamous cell carcinoma. Laryngoscope 2010;120:58-61.

13 Deganello A, Meccariello G, Bini B, et al. Is elective neck dissection necessary in cases of laryngeal recurrence after previous radiotherapy for early glottic cancer? J Laryngol Otol 2014;128:1089-94.

14 Pezier TF, Nixon IJ, Scotton W, et al. Should elective neck dissection be routinely performed in patients undergoing salvage total laryngectomy? J Laryngol Otol 2014;128:279-83.

15 León X, Orús C, Quer M. Design, maintenance, and exploitation of an oncologic database for patients with malignant tumours of the head and neck. Acta Otorrinolaringol Esp 2002;53:185-90.

16 Sobin LH, Gospodarowicz MK, Wittekind C. TNM Classification of Malignant Tumours. $7^{\text {th }}$ ed. Chichester, England: Wiley-Blackwell; 2009.

17 Koss SL, Russell MD, Leem TH, et al. Occult nodal disease in patients with failed laryngeal preservation undergoing surgical salvage. Laryngoscope 2014;124:421-8.

18 Lee DJ, Kwon KH, Chung EJ, et al. The role of elective neck dissection during salvage surgery in head and neck squamous cell carcinoma. Acta Otolaryngol 2013;133:886-92.

19 Prendes BL, Aubin-Pouliot A, Egbert N, et al. Elective lymphadenectomy during salvage for locally recurrent head and neck squamous cell carcinoma after radiation. Otolaryngol Head Neck Surg 2014;151:462-7.

20 Deschamps DR, Spencer HJ, Kokoska MS, et al. Implications of head and neck cancer treatment failure in the neck. Otolaryngol Head Neck Surg 2010;142:722-7.

21 León X, Gañán L, Costey M, et al. Isolated lymphatic recurrences in patients with head and neck carcinomas. Acta Otorrinolaringol Esp 2003;54:710-7.

22 Sanabria A, Silver CE, Olsen KD, et al. Is elective neck dissection indicated during salvage surgery for head and neck squamous cell carcinoma? Eur Arch Otorhinolaryngol 2014;271:3111-9.

23 Burge JS. Histological changes in cervical lymph nodes following clinical irradiation. Proc R Soc Med 1985;68:77-9.

24 Jonsson K, Libshitz HI, Osborne BM. Lymphangiographic changes after radiation therapy. AJR Am J Roentgenol 1978;131:803-6.

25 Gourin CG, Conger BT, Porubsky ES, et al. The effect of occult nodal metastases on survival and regional control in patients with head and neck squamous cell carcinoma. Laryngoscope 2008;118:1191-4.

${ }^{26}$ Cerezo L, López C, de la Torre A, et al. Incidence of human papillomavirus-related oropharyngeal cancer and outcomes after chemoradiation in a population of heavy smokers. Head Neck 2014;36:782-6.

27 Rodrigo JP, Heideman DA, García-Pedrero JM, et al. Time trends in the prevalence of HPV in oropharyngeal squamous cell carcinomas in northern Spain (1990-2009). Int J Cancer 2014;134:487-92.

28 Kostakoglu L, Fardanesh R, Posner M, et al. Early detection of recurrent disease by FDG-PET/CT leads to management changes in patients with squamous cell cancer of the head and neck. Oncologist 2013;18:1108-17. 
29 Rangaswamy B, Fardanesh MR, Genden EM, et al. Improvement in the detection of locoregional recurrence in head and neck malignancies: F-18 fluorodeoxyglucose-positron emission tomography / computed tomography compared to high resolution contrast-enhanced computed tomography and endoscopic examination. Laryngoscope 2013;123:2664-9.

${ }^{30}$ Gupta T, Master Z, Kannan S, et al. Diagnostic performance of post-treatment FDG PET or FDG PET/CT imaging in head and neck cancer: a systematic review and meta-analysis. Eur J Nucl Med Mol Imaging 2011;38:2083-95.

$31 \mathrm{Ng} \mathrm{SH}$, Yen TC, Chang JT, et al. Prospective study of [18F] fluorodeoxyglucose positron emission tomography and com- puted tomography and magnetic resonance imaging in oral cavity squamous cell carcinoma with palpably negative neck. J Clin Oncol 2006;20;24:4371-6.

32 Roh JL, Park JP, Kim JS, et al. 18F-fluorodeoxyglucose PET/ $C T$ in head and neck squamous cell carcinoma with negative neck palpation findings: a prospective study. Radiology 2014;271:153-61.

33 Gilbert MR, Branstetter BF, Kim S. Utility of positron-emission tomography/computed tomography imaging in the management of the neck in recurrent laryngeal cancer. Laryngoscope 2012;122:821-5.

Received: August 4, 2016 - Accepted: May 4, 2017

Address for correspondence: Cristina Valero, Hospital de la Santa Creu i Sant Pau Otorhinolaryngology Department, 90 Mas Casanovas street, 08041 Barcelona, Spain. Tel. +34 93 5565679. Fax +34 93 5565604. E-mail: cvalero@ santpau.cat 